\title{
Mesenchymal Stem Cells Improve Muscle Function Following Single Stretch Injury: A Preliminary Study
}

\author{
Stacey Brickson ${ }^{1, *}$, Patrick Meyer ${ }^{2}$, Erin Saether ${ }^{1}$ and Ray Vanderby Jr. ${ }^{1,3}$ \\ 1 Department of Orthopedics and Rehabilitation, University of Wisconsin, Madison, WI 53705, USA; \\ esaether210@gmail.com (E.S.); vanderby@ortho.wisc.edu (R.V.) \\ 2 School of Medicine and Public Health, University of Wisconsin, Madison, WI 53705, USA; \\ pmeyer@uwhealth.org \\ 3 Department of Biomedical Engineering, University of Wisconsin, Madison, WI 53705, USA \\ * Correspondence: brickson@ortho.wisc.edu; Tel.: +1-608-265-0487; Fax: +1-608-262-2989
}

Academic Editors: Giuseppe Musumeci and Marta Anna Szychlinska

Received: 24 October 2016; Accepted: 8 December 2016; Published: 15 December 2016

\begin{abstract}
Stem cells have shown promise as a therapeutic intervention by enhancing skeletal muscle regeneration following muscle injury. The purpose of this study was to determine the effect of mouse mesenchymal stem cells (MSCs) on muscle function following a single stretch injury in the calf muscle of C57BL/67 mice. A custom isokinetic device was used to induce a single stretch injury. An intramuscular injection of MSCs or saline was administered three days post-injury. Mechanical testing to measure peak isometric joint torque in vivo was done immediately and at seven or 14 days post-injury. Susceptibility to reinjury was assessed in the soleus muscle using an in situ repeated eccentric contraction (ECC) protocol. In vivo isometric torque of the plantar flexors dropped immediately following stretch injury by $50 \%$. Treatment with MSCs attenuated the torque deficit at seven days, while there were no differences in torque deficit between groups at 14 days. In situ ECC testing of the soleus showed a significant specific force drop following injury, with the MSC group demonstrating a protective effect at seven and 14 days. These results demonstrate transient improvement in isometric torque and reduced susceptibility to reinjury following single stretch injury with intramuscular injection of MSCs.
\end{abstract}

Keywords: muscle strain; stem cells; healing; mechanical testing; mouse

\section{Introduction}

Muscle injuries are a common problem encountered by clinicians, with muscle strains accounting for up to $30 \%$ of a typical sports medicine practice [1]. Without complete healing, there is a high risk of reinjury after muscle strain. Recurrent injuries are often more severe than the initial injury and result in prolonged periods away from activity [2]. Thus, much research has focused on therapeutic interventions to enhance muscle healing following injury.

Muscle injuries proceed through stages of healing, including: degeneration, inflammation, regeneration, and fibrosis [3]. Muscle has the ability to regenerate itself via normally quiescent precursor cells called satellite cells that become activated to differentiate into muscle fibers after injury [4]. This regenerative capacity is balanced with the need to stabilize the disrupted muscle fibers through the deposition of collagen. While fibrosis initially supports the injured muscle, the continued expansion of the collagen deposition restricts the regenerative potential of the muscle and renders the muscle with inferior mechanical properties [5]. The inflammatory response that results following injury appears to mediate muscle healing by playing a role in both regeneration and fibrosis [6]. Non-steroidal anti-inflammatory drugs (NSAIDs) are commonly prescribed to reduce the inflammatory phase of muscle injury and prevent further secondary damage to the muscle. While dampening the 
inflammatory cascade lowers pain and increases short-term mobility [7], many studies have shown that NSAIDs may decrease long-term strength recovery by limiting muscle regeneration $[8,9]$. Thus, while the goal of altering the delicate balance in the inflammatory cascade is to improve muscle regeneration, it may also compromise healing.

Attempts to augment the regenerative phase of injured skeletal muscle have strived to harness the regenerative potential of different stem cell populations. It has been shown previously that myoblasts from expanded primary cultures injected into severely damaged skeletal muscle can improve muscle regeneration and force development in mice [10]. However, numerous limitations of myoblast transplantation, including poor cell survival and migratory ability of cells at the site of injury, have made application of this therapy difficult. Subsequently, a novel population of muscle-derived stem cells (MDSCs) was reported in mice that possess enhanced survival and regenerative potential in vivo, offering significantly improved cell transplantation [11]. In fact, more recently, MDSCs were demonstrated to significantly improve muscle regeneration, decrease fibrosis and enhance functional recovery following intramuscular injection in mice [12]. Several studies have reported that bone-marrow-derived mesenchymal stem cells (MSCs) can also contribute to skeletal muscle healing and improve functional recovery $[13,14]$. The degree of functional recovery using MSCs appears to be dependent upon the number of MSCs injected [15]. Recently, isolated bone-marrow cells injected intravenously into mice were found to migrate to the site of injury and improve the functional recovery of the muscle [16]. Many benefits of MSC transplantation are attributed to a strong paracrine capacity, including increased angiogenesis, decreased fibrosis, immunomodulation, and secretion of survival and stem cell recruitment factors [17]. Gene expression in the injury microenvironment also appears optimally altered by the presence of stem cells to promote angiogenesis and myogenesis and limit fibrosis [18]. Taking advantage of the pro-regenerative properties of stem cells to regulate endogenous tissue regeneration via this mechanism is promising for clinical intervention.

Studies to date investigating muscle regeneration and functional recovery have employed a wide variety of injury models, including repetitive cyclic contractions, lacerations, and contusions. Although the phases of healing remain similar across injury models, functional recovery of the muscle varies [3]. In order to evaluate how differing therapies impact regeneration and susceptibility to reinjury, a model that mimics the mechanism of common musculoskeletal injuries seen clinically is crucial. Our lab has recently engineered a device that produces a single-stretch injury in the calf muscles of mice that is standardized, reproducible, and similar to strain injuries seen clinically [19]. The goal of this study is to evaluate the effectiveness of MSCs as a therapeutic intervention for enhancing functional recovery following a clinically relevant muscle strain injury in mice. Results from this study will help clarify the effectiveness of MSCs and work towards finding a therapy that is able to promote optimal recovery and minimize the incidence of reinjury.

\section{Materials and Methods}

\subsection{Instrumentation and Experimental Apparatus}

A custom device was designed and fabricated that would induce a reproducible stretch injury in mouse Achilles tendons via a single isokinetic dorsiflexion of the ankle. A geared electric motor (Faulhaber Model 3863A024C + 38/2S43:1 + X0744 low inertia gear motor, MICROMO, Clearwater, FL, USA) was controlled by a custom designed closed loop system (signals supplied by Wavetek arbitrary waveform generator Model 75, Wavetek Corp, San Diego, CA, USA). The device included torque and angular position sensors and a nerve stimulator [19]. A custom modified precision potentiometer (Vishay/Spectrol model 138-0-0-103, Vishay Americas, Shelton, CT, USA) measured angular position. A custom cruxiform torsional load cell with a full scale range of $100 \mathrm{mN} \cdot \mathrm{m}$ was fabricated. Torque, angular displacement and time were recorded with Data Translation Measure Foundry data acquisition software (Data Translation Inc., Marlboro, MA, USA) on a Dell computer (Dell Inc., Round Rock, TX, USA) using a 16 bit Data Translation model DT322 data acquisition board. 


\subsection{Experimental Injury Protocol}

The animal protocol was approved by the University of Wisconsin Institutional Animal Care and Use Committee. Twenty-four male C57BL/67 wild type 12-week-old mice, with body weight $25.33 \pm 0.43 \mathrm{~g}$ (Jackson Laboratory, Bar Harbor, ME, USA) were randomly assigned to one of four groups ( $n=6$ /group). The groups were: sham saline, sham MSC, injured saline and injured MSC injection. Animals from each group were evaluated at two time points, 7 or 14 days post-injury. The mice were anesthetized with isoflurane and placed in a side lying position on a metal half cylinder warming unit to maintain body temperature at $37^{\circ} \mathrm{C}$. A 2-mm incision exposed the Achilles tendon. Each animal was positioned so that the axis of ankle joint rotation was aligned with the axis of rotation of the loading frame. The foot was secured to a plate and locked in its neutral position (tibiotarsal angle of $90^{\circ}$ perpendicular to the tibia). A custom splint placed over the femur and tibia ensured that the knee joint angle remained at $0^{\circ}$ throughout the test. The Achilles tendon was shortened $1.4 \mathrm{~mm}$ using a bifurcated pin system connected to a precision potentiometer. The plantar flexors were stimulated to tetany ( $2.8 \mathrm{~mA}$ pulse train, $100 \mathrm{~Hz}, 2.0 \mathrm{~ms}$ pulse width and triangular wave) with a needle electrode inserted subcutaneously in the popliteal fossa. A $1.0 \mathrm{~s}$ trigger delay between the initial muscle stimulation and ankle rotation ensured complete muscle tetany. After the tendon was shortened, muscle stimulation and stretch injury were executed over $1.675 \mathrm{~s}$. The angular velocity was $450^{\circ} / \mathrm{s}$ as the ankle was rotated from neutral through a $75^{\circ}$ arc into dorsiflexion and returned to neutral, at which time the muscle stimulation ceased.

\subsection{Mesenchymal Stem Cell Culture}

Mouse mesenchymal stem cells were purchased (Life Technologies, Grand Island, NY, USA) at passage 8 and expanded to passages 9 and 10 for in vivo application. Prior to purchase, MSCs were collected from the bone marrow of C57BL/ 6 mice at $\leq 8$ week gestation. Cell markers were analyzed by the commercial source using flow cytometry to ensure that cells expressed CD29, CD34, CD44, Sca-1 $(>70 \%)$, and did not express CD117 $(<5 \%)$. Tri-lineage differentiation potential (osteogenic, adipogenic, and chondrogenic) was confirmed by the manufacturer. Once cells were received, they were seeded in T175 flasks and cultured using D-MEM/F-12 with glutamax (Life Technologies) containing 10\% Fetal Bovine Serum (FBS, Life Technologies) and Gentamicin ( $5 \mu \mathrm{g} / \mathrm{mL}$, Life Technologies). Cells were maintained at $37^{\circ} \mathrm{C}$ and $5 \% \mathrm{CO}_{2}$ in a humidified incubator and media was changed every $2-3$ days. Cells were viewed daily to ensure cell health including a spindle-like appearance and were passaged upon reaching $70 \%-80 \%$ confluency. The day of surgery, cells were collected using TrypLE Express (Life Technologies), washed, and fluorescently labeled with Celltracker CM-DiI (Life Technologies). Once the fluorescent membrane dye was applied, cells were counted and suspended in Dulbecco's phosphate buffered saline (DPBS, Life Technologies) at a concentration of $1 \times 10^{6}$ cells $/ 100 \mu \mathrm{L}$ DPBS. $4^{\prime}$,6-diamidino-2-phenylindole (DAPI) counterstain and negative control for auto fluorescence were not performed. Intramuscular injections of $5 \times 10^{5} \mathrm{MSC}$ in $50 \mu \mathrm{L}$ DPBS or $50 \mu \mathrm{L}$ of DPBS were performed 3 days post-injury or sham, respectively.

\subsection{Histology and Immunohistochemistry}

The Achilles tendon was transected and the calf muscle resected. The gastrocnemius was isolated, dissected and frozen in isopentane cooled in liquid nitrogen and stored at $-80^{\circ} \mathrm{C}$. Serial $10 \mu \mathrm{m}$ cross-sections were obtained using a cryostat (Leica/Jung CM 1800 model, IMEB, Inc., San Marcos, CA, USA) and subsequently stained with hematoxylin and eosin (H\&E) and Masson's Trichrome. Immunostaining for vimentin (1:200, Abcam, Cambridge, UK) was performed according to standard immunohistochemistry (IHC) protocols. Micrographs were collected using a camera-assisted microscope (Nikon Eclipse microscope model E6000, Nikon Instruments, Inc., Mellville, NY, USA with an Olympus camera, model DP70, Olympus Imaging America, Inc., Center Valley, PA, USA). 
Five sections from each muscle were viewed and two computer images were captured per section and viewed using Image J (National Institutes of Health, Bethesda, MD, USA).

\subsection{Isometric Peak Torque}

In vivo mechanical testing of isometric peak torque was done immediately and at 7 or 14 days post-injury. The Achilles tendon was released from the roller-clamp system following injury. The load frame was fixed so that isometric torque could be recorded in a neutral position. The plantar flexors were stimulated to tetany. Two isometric peak torques were recorded with $3 \mathrm{~min}$ rest intervals between tests and the average torque was calculated. Incisions were closed with Vetbond (MWI Veterinary Supply Co., Boise, ID, USA) and animals were returned to their cages. Isometric torque measurements were again recorded at 7 or 14 days post-injury in the absence of Achilles tendon shortening.

\subsection{Eccentric Contraction Testing}

Susceptibility to reinjury was assessed in the soleus muscle by subjecting it to an in situ eccentric contraction (ECC) protocol, which consists of five maximal tetanic stimulations [20]. The soleus muscles were dissected and allowed to equilibrate in calcium Ringer's solution. In addition, a 4/0 silk suture was used to attach the proximal tendon to a rigid support and the distal tendon to a servomotor (Model 300B-LR, Aurora Scientific, Toronto, ON, Canada) in a bath filled with Ringer's solution, continually gassed with $95 \% \mathrm{O}_{2} / 5 \% \mathrm{CO}_{2}$ to maintain $\mathrm{pH} 7.6$ at $30{ }^{\circ} \mathrm{C}$. The muscles were stimulated with a single pulse and progressively lengthened until an optimal length $\left(\mathrm{L}_{0}\right)$ was reached. Protection against mechanical injury was assessed by subjecting each muscle to five maximal tetanic stimulations at a frequency of $150 \mathrm{~Hz}$. Each ECC involved tetanic stimulation for $700 \mathrm{~ms}$, with a stretch of $0.5 \mathrm{~L}_{0} / \mathrm{s}$ over the final $200 \mathrm{~ms}$ to result in a total stretch of $0.1 \mathrm{~L}_{0}$. Five minutes of recovery time was allowed between each measurement. Force drop was calculated as ((ECC1-ECC5)/ECC1). Force drop across contractions was measured and normalized to cross-sectional area $\left(\mathrm{mN} / \mathrm{mm}^{2}\right)$.

\subsection{Statistical Analyses}

Differences in mechanical data were assessed by two-way ANOVA. Values are means \pm SEM.

\section{Results}

\subsection{MSC Localization}

Injured gastrocnemius muscles were analyzed at day 7 post-injury to ensure MSC delivery and viability. MSCs flouresced red and were detected within the injured muscle tissue (Figure 1).

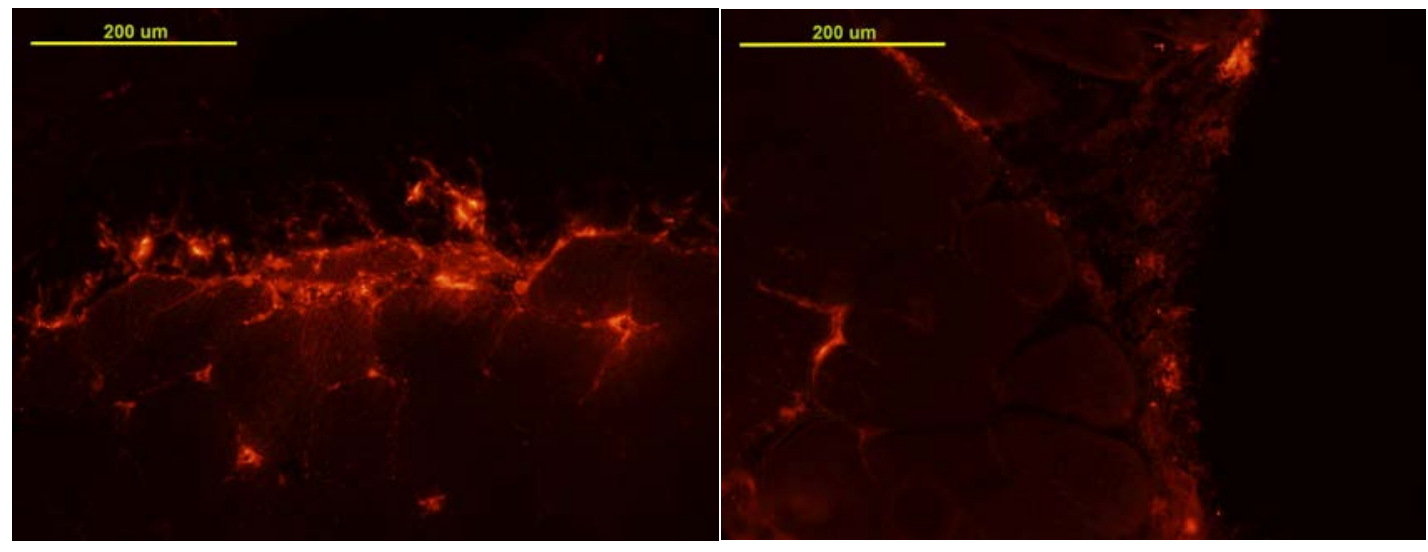

Figure 1. Mesenchymal stem cells (MSCs) were stained red using Celltracker CM-DiI. At day 7 post-injury, MSCs were detected in injured gastrocnemius muscles that received MSC injections three days post-injury. 


\subsection{Histology and Immunohistochemistry}

Masson's Trichrome, vimentin and H\&E images for injured gastrocnemius muscles treated with saline (left column) or MSCs (right column) are presented in Figure 2. Data is qualitative and preliminary.

(A)

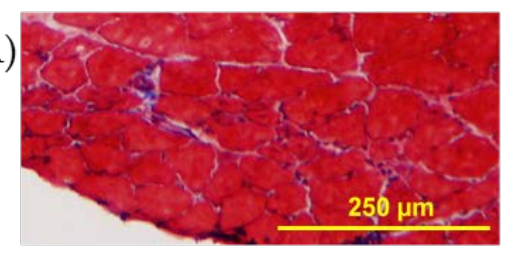

(C)

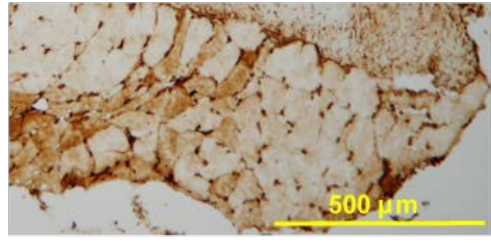

(E)

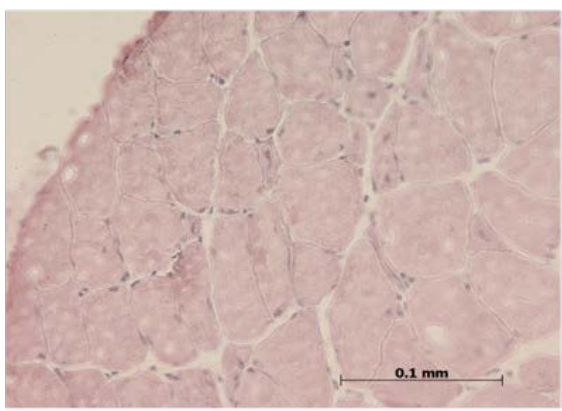

(B)

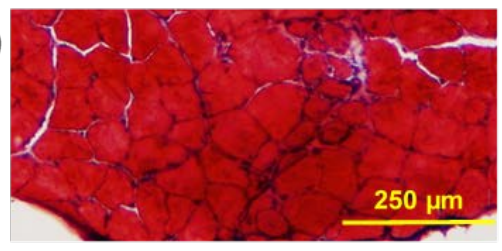

(D)

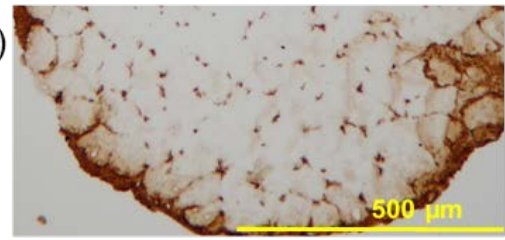

(F)

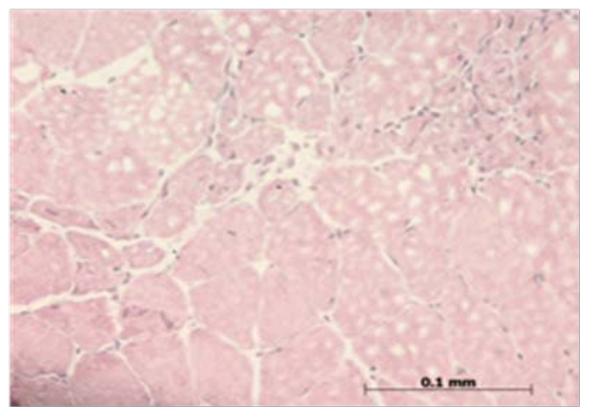

Figure 2. Injured muscles treated with saline (left column) or MSCs (right column) and stained with Masson's (A,B), vimentin, (C,D), and hematoxylin and eosin (H\&E) (E,F).

\subsection{Isometric Peak Torque}

In vivo isometric peak torque of the plantar flexors was measured before and immediately following stretch injury, and then again at seven or 14 days post-injury. Isometric peak torque was expressed as a percentage deficit (Figure 3). The immediate drop in torque was similar between groups, as was anticipated since MSCs were not injected until three days post-injury. Torque declined by $51.20 \% \pm 9.7 \%$ in the injured group to receive saline and $60.23 \% \pm 4.0 \%$ in the injured group to receive MSCs. There was an interaction between time and treatment $(p<0.05)$, with the injured MSC group experiencing a slight improvement in isometric peak torque deficit seven days post-injury $(39.72 \% \pm 10.24 \%, p<0.05)$ but not the saline group $(65.37 \% \pm 4.02 \%)$. After 14 days, there were no differences in torque deficit between the injured groups receiving saline and MSCs, $43.98 \% \pm 4.0 \%$ and $48.61 \% \pm 6.8 \%$, respectively. 


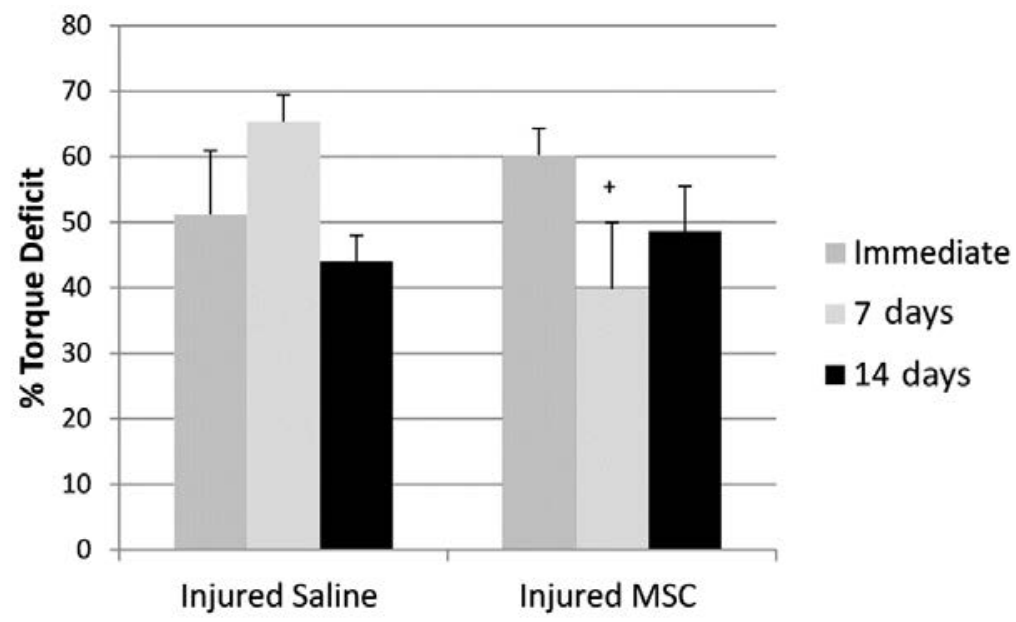

Figure 3. Isometric peak torque deficit of the plantar flexors following stretch injury, $+p<0.05$.

\subsection{Eccentric Contraction Testing}

In situ ECC testing of the soleus commenced within an hour of in vivo testing. Specific force over a series of eccentric contractions dropped in the injured animals receiving saline injection by $15.59 \% \pm 0.60 \%$ seven days post-injury (Figure 4 A sample trace). A similar deficit of $16.85 \% \pm 6.5 \%$ remained after 14 days. The group receiving MSCs conferred a protective effect at seven days and 14 days, with specific force deficits of $4.70 \% \pm 3.4 \%$ (Figure $4 \mathrm{~B}$ sample trace) and $5.47 \% \pm 0.23 \%$, respectively. Specific force drop without injury (sham) with the ECC protocol was $2.74 \% \pm 2.35 \%$ and $3.37 \% \pm 4.5 \%$ for the saline and MSC treated groups, respectively. There was a significant treatment effect, showing a protective effect of MSCs on susceptibility to reinjury at seven days $(p<0.001)$ and 14 days $(p<0.01)$ (Figure 5$)$.
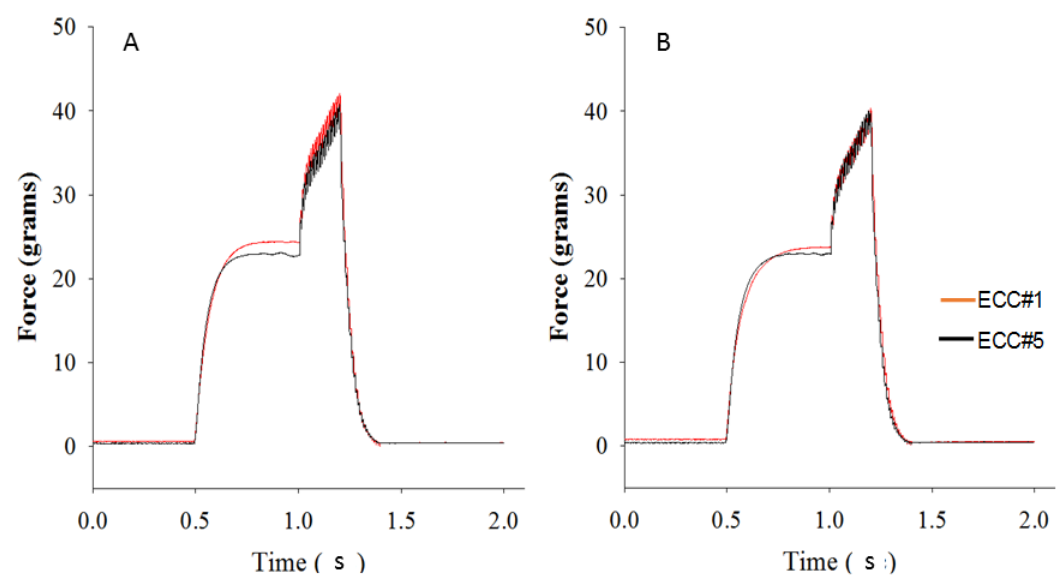

Figure 4. Force tracings of tested injured soleus muscles. Drop in tetanic force between the first eccentric contraction (ECC) (red) and fifth ECC (black) tetanic lengthening test in (A) saline and (B) MSC treated mice seven days post-injury. 


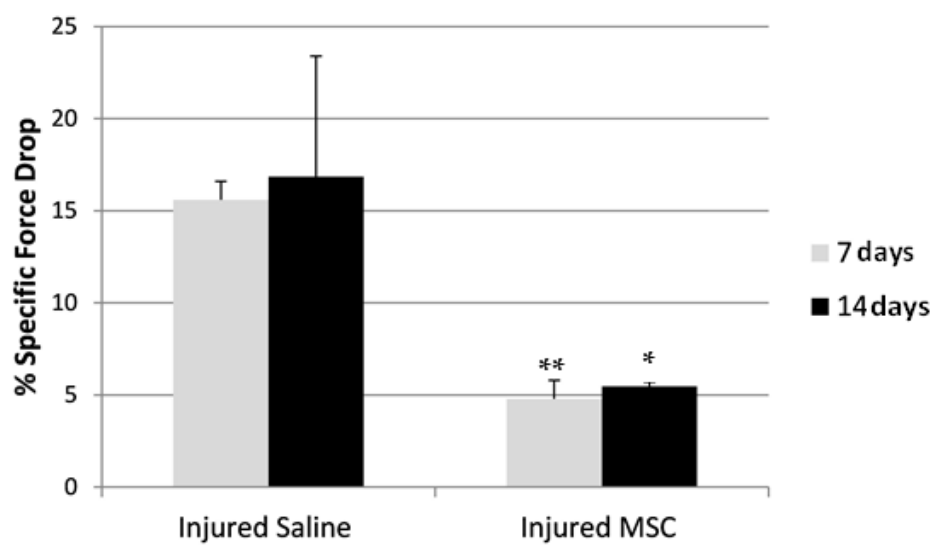

Figure 5. Specific force deficit in the soleus muscle following repeated eccentric contractions, ** $p<0.001 ; * p<0.01$.

\section{Discussion}

Complete healing following muscle injury has been the focus of many recent investigations, including approaches to alter the inflammatory cascade [21,22] and introduction of stem cell therapy $[12,23,24]$. This study provides a novel method of inducing injury that is mechanistically relevant to the eccentric or strain injuries seen clinically [19]. While the inflammatory cascade does not differentiate between injuries sustained via strain, contusion, ischemia-reperfusion or chemical induction, susceptibility to reinjury may be unique to the manner in which the fibers are damaged, since strain affects the fibers located close to the myotendinous junction [25]. This study provides evidence that MSCs offer a protective effect for reinjury following stretch injury, as described by an attenuated specific force deficit following repeated lengthening contractions.

The timing of therapies such as MSC delivery following injury is paramount to optimal healing. Several landmark studies have explored the optimal timing for stem cell injection $[5,12,26]$, providing evidence that delayed injections are most effective and operate through paracrine pathways. Peak expression of transforming growth factor- $\beta 1$ (TGF- $\beta 1$ ) has been shown to occur two to three days after muscle injury $[27,28]$ and can promote fibrosis at the injury site by acting directly on host cells and injected MDSCs when injected immediately [12]. Conversely, angiogenesis begins at three days and peaks five days post-injury [29], such that introduction of MDSCs at this time promotes angiogenesis through high vascular endothelial growth factor (VEGF) expression [12]. Intramuscular injection of MSCs seven days following skeletal muscle injury in rats led to a downregulation of TGF- $\beta 1$ and fibrosis [23]. While injection of MDSCs at four and seven days post-injury minimized fibrosis, muscle strength was improved only with injection at the earlier time point [12]. Our data suggests that injection of MSCs three days post-injury was sufficient to attenuate peak torque deficit in the early stages of healing but failed to maintain its protective effect during the peak of the regenerative phase.

Enhanced function and resistance to reinjury has been correlated with improved regeneration and the reduction of fibrosis [30]. A limitation of this study is the absence of morphological data to characterize fibrosis; a limited number of available images made observations preliminary and qualitative, precluding quantification of fibrosis. While we lack histological evidence, our mechanical findings suggest improved muscle function with intramuscular injection of MSCs. Isometric peak torque is a non-invasive in vivo physiologic assessment of function that allows for longitudinal testing [31,32]. Undeniably, in vivo assays for muscle function have limitations. Torque is relative to muscle mass and cross-sectional area, which were not measured, and, therefore, percent deficits were reported instead of absolute values. Determination of the contribution of each plantar flexor to overall function is limited in most, but not all, testing models [33]. Despite these limitations, mechanical assessment of function through isometric peak torque revealed an improvement in the MSC treated group at seven days, while the saline treated group experienced a further decline. This further 
reduction in function has been well documented in the literature and characterized by inflammatory changes within the muscle $[34,35]$. Peak isometric torque deficits in both groups were similar at 14 days, suggesting that the protection provided by MSCs was no longer evident. In other models of muscle strain, continued decrement in strength over the early post-injury period has been noted with the administration of NSAIDs [36]. Further investigations are required to determine if an additional injection of MSCs would have promoted continued protection or delayed muscle regeneration.

It is well known that muscle injuries are recurrent. Reinjuries to original sites of trauma are the most severe and result in the greatest amount of time lost from activities [2,37]. While contractile force provides an accepted measure of functional recovery $[16,38,39]$, an alternative metric for vulnerability to reinjury is contractile force following repeated eccentric contractions, which can reflect impairments of the contractile machinery or increased susceptibility to fatigue [40]. Fatigue as a risk factor for strain injuries has been observed clinically [2] and tested experimentally [41]. Diminished contractile force from repeated contractions renders muscle less capable of absorbing high loads, thereby significantly increasing risk of injury.

Therefore, in addition to isometric peak torque deficits, protection against mechanical reinjury was assessed by subjecting the soleus muscles to a repeated eccentric contraction protocol. Our ECC protocol rendered a small drop in max tetanic force in the uninjured (sham) soleus of $3 \%$. The same ECC protocol elicited a 20\% drop in max tetanic force generation in extensor digitorum longus (EDL) muscles of wild type mice compared to a $35 \%$ drop in dystrophin-deficient mice (MDX) EDLs [20]. This difference is likely due to the slow twitch fiber composition of the soleus compared to the EDL. ECC following single stretch injury resulted in max tetanic force deficits in the soleus comparable to the EDL in wild type mice, $15.59 \%$ and $16.85 \%$ at seven and 14 days, respectively. Injection of MSCs provided protection against a drop in specific force following repeated ECC at both seven and 14 days post-injury, $4.70 \%$ and $5.47 \%$, respectively. While research efforts have elucidated this mechanism of strain injury, a critical threshold for diminished tetanic force has not been established. Regardless, a significant reduction in tetanic force decrement noted in the injured MSCs confers improved the ability of the muscle to absorb load and ameliorate the risk of reinjury.

It is important to consider the discrepancies in muscle function based on the mechanical testing protocol at 14 days, with continued protection offered in the MSC group with in situ ECC testing and lack thereof with in vivo isometric peak torque testing. While all plantar flexors in the model are subject to stretch injury, it is known that biarticular muscles are more prone to disruption $[1,42]$, and that fast twitch fibers appear to be more vulnerable, possibly due to metabolic profile $[43,44]$, higher tensions [45] or relatively shorter optimal lengths of the motor unit [46]. The gastrocnemius is comprised primarily of fast twitch fibers (95\% IIB), while the uniarticular soleus muscle is made up of slow twitch (I and IIA) fibers [47]. In vivo isometric peak torque testing does not determine the relative torque contributions of the various plantar flexor muscles, whereas in situ testing was exclusive for the soleus. This muscle was selected for testing as it has a long slender tendon at the head of the fibula and can be separated from the gastrocnemius at the Achilles tendon, resulting in readily attachable tendons at both ends. The soleus, EDL and tibialis anterior are often utilized for in situ testing for this reason, while the gastrocnemius architecture is not conducive to in situ testing. From these data, we conclude that MSCs may confer protection against reinjury in the soleus, but it is less clear how the gastrocnemius may respond.

This work contributes to our understanding of muscle injuries most commonly seen clinically, involving an eccentric contraction or single stretch, evoking damage to the musculotendinous junction $[19,48]$. While the healing cascade is similar among all types of muscle injuries, it is unclear if the risk of reinjury is the same for contusion, ischemia-reperfusion, repeated eccentric contractions or a single stretch injury. Therefore, this work introduces a new approach to injury in skeletal muscle and provides a segue for more extensive investigations into stem cell therapy, and mechanisms of regeneration and repair. To our knowledge, there are no reports of the rate of reinjury following muscle injury in an animal model. There are a plethora of studies reporting in situ measures of function, and histological or imaging evidence for reduced fibrosis, which correlates with reduced risk of reinjury. 
This study provides mechanical testing that suggests MSCs reduce the risk of reinjury. Treatment strategies for muscle injuries have been largely stagnant over the past few decades, consisting of rest, ice, compression, elevation, and exercise. Exciting advances in stem cell therapies aimed at minimizing fibrosis and accelerating functional recovery have exploded in the past decade. Full elucidation of the pathophysiology of injury, and the impact of stem cells on the complex cascade of regeneration and repair are paramount for translation into clinical studies. The potential for stem cell therapy to shorten the recovery period, minimize recurrent injury risk, and restore function to pre-injury levels would alter the landscape of muscle strain morbidity. This preliminary study contributes a clinically relevant mechanism for muscle injury with mechanical data to support improved function and minimized risk for reinjury subsequent to MSC injection.

This study does not explore mechanisms through which MSCs may have directly or indirectly through paracrine signaling altered the inflammatory cascade resulting in improved mechanical function. Limitations of this study include lack of DAPI counterstain, laminin staining, and negative control necessary to fully appreciate the location and incorporation of MSCs. We provide only mechanical data to support the therapeutic benefits of stem cell therapy. This is a preliminary study and further studies are needed to confirm our results. Future directions include more comprehensive studies to explore gene expression of inflammatory cytokines, immunohistochemistry to quantify regeneration and fibrosis, and an extended timeline to assess the risk of reinjury.

\section{Conclusions}

Intramuscular injection of MSCs improved muscle function following single stretch injury in the calf muscle of mice. While improvements in isometric torque deficits were transient, susceptibility to fatigue was reduced for 7 and 14 days following stretch injury. These results suggest that MSCs may confer a protective effect for the risk of reinjury.

Acknowledgments: This work was supported by Research Grants from the University of Wisconsin Department of Orthopedics and Rehabilitation (PRJ33NB).

Author Contributions: Stacey Brickson conceived and designed the experiments, analyzed the data and wrote the paper; Patrick Meyer and Erin Saether performed the experiments; Ray Vanderby Jr. contributed reagents/materials/laboratory.

Conflicts of Interest: The authors declare no conflict of interest.

\section{References}

1. Garrett, W.E., Jr. Muscle strain injuries. Am. J. Sports Med. 1996, 24, S2-S8. [PubMed]

2. Brooks, J.H.; Fuller, C.W.; Kemp, S.P.; Reddin, D.B. Incidence, risk, and prevention of hamstring muscle injuries in professional rugby union. Am. J. Sports Med. 2006, 34, 1297-1306. [CrossRef] [PubMed]

3. Huard, J.; Li, Y.; Fu, F.H. Muscle injuries and repair: Current trends in research. J. Bone Joint Surg. Am. 2002, 84, 822-832. [CrossRef] [PubMed]

4. Hurme, T.; Kalimo, H. Activation of myogenic precursor cells after muscle injury. Med. Sci. Sports Exerc. 1992, 24, 197-205. [CrossRef] [PubMed]

5. Li, Y.; Huard, J. Differentiation of muscle-derived cells into myofibroblasts in injured skeletal muscle. Am. J. Pathol. 2002, 161, 895-907. [CrossRef]

6. Tidball, J.G. Inflammatory processes in muscle injury and repair. Am. J. Physiol. Regul. Integr. Comp. physiol. 2005, 288, R345-R353. [CrossRef] [PubMed]

7. Mishra, D.K.; Friden, J.; Schmitz, M.C.; Lieber, R.L. Anti-inflammatory medication after muscle injury. A treatment resulting in short-term improvement but subsequent loss of muscle function. J. Bone Joint Surg. Am. 1995, 77, 1510-1519. [CrossRef] [PubMed]

8. Almekinders, L.C. Anti-inflammatory treatment of muscular injuries in sport. An update of recent studies. Sports Med. 1999, 28, 383-388. [CrossRef] [PubMed]

9. Shen, W.; Li, Y.; Tang, Y.; Cummins, J.; Huard, J. Ns-398, a cyclooxygenase-2-specific inhibitor, delays skeletal muscle healing by decreasing regeneration and promoting fibrosis. Am. J. Pathol. 2005, 167, 1105-1117. [CrossRef] 
10. Irintchev, A.; Langer, M.; Zweyer, M.; Theisen, R.; Wernig, A. Functional improvement of damaged adult mouse muscle by implantation of primary myoblasts. J. Physiol. 1997, 500, 775-785. [CrossRef] [PubMed]

11. Jankowski, R.J.; Deasy, B.M.; Huard, J. Muscle-derived stem cells. Gene Ther. 2002, 9, 642-647. [CrossRef] [PubMed]

12. Ota, S.; Uehara, K.; Nozaki, M.; Kobayashi, T.; Terada, S.; Tobita, K.; Fu, F.H.; Huard, J. Intramuscular transplantation of muscle-derived stem cells accelerates skeletal muscle healing after contusion injury via enhancement of angiogenesis. Am. J. Sports Med. 2011, 39, 1912-1922. [CrossRef] [PubMed]

13. Matziolis, G.; Winkler, T.; Schaser, K.; Wiemann, M.; Krocker, D.; Tuischer, J.; Perka, C.; Duda, G.N. Autologous bone marrow-derived cells enhance muscle strength following skeletal muscle crush injury in rats. Tissue Eng. 2006, 12, 361-367. [CrossRef] [PubMed]

14. Dezawa, M.; Ishikawa, H.; Itokazu, Y.; Yoshihara, T.; Hoshino, M.; Takeda, S.; Ide, C.; Nabeshima, Y. Bone marrow stromal cells generate muscle cells and repair muscle degeneration. Science 2005, 309, 314-317. [CrossRef] [PubMed]

15. Winkler, T.; von Roth, P.; Matziolis, G.; Mehta, M.; Perka, C.; Duda, G.N. Dose-response relationship of mesenchymal stem cell transplantation and functional regeneration after severe skeletal muscle injury in rats. Tissue Eng. Part A 2009, 15, 487-492. [CrossRef] [PubMed]

16. Corona, B.T.; Rathbone, C.R. Accelerated functional recovery after skeletal muscle ischemia-reperfusion injury using freshly isolated bone marrow cells. J. Surgical Res. 2014, 188, 100-109. [CrossRef] [PubMed]

17. Gnecchi, M.; Zhang, Z.; Ni, A.; Dzau, V.J. Paracrine mechanisms in adult stem cell signaling and therapy. Cir. Res. 2008, 103, 1204-1219. [CrossRef] [PubMed]

18. Shi, M.; Ishikawa, M.; Kamei, N.; Nakasa, T.; Adachi, N.; Deie, M.; Asahara, T.; Ochi, M. Acceleration of skeletal muscle regeneration in a rat skeletal muscle injury model by local injection of human peripheral blood-derived CD133-positive cells. Stem Cells 2009, 27, 949-960. [CrossRef] [PubMed]

19. Brickson, S.L.; McCabe, R.P.; Pala, A.W.; Vanderby, R., Jr. A model for creating a single stretch injury in murine biarticular muscle. BMC Sports Sci. Med. Rehabil. 2014, 6, 14. [CrossRef] [PubMed]

20. Sonnemann, K.J.; Fitzsimons, D.P.; Patel, J.R.; Liu, Y.; Schneider, M.F.; Moss, R.L.; Ervasti, J.M. Cytoplasmic $\gamma$-actin is not required for skeletal muscle development but its absence leads to a progressive myopathy. Dev. Cell 2006, 11, 387-397. [CrossRef] [PubMed]

21. Terada, S.; Ota, S.; Kobayashi, M.; Kobayashi, T.; Mifune, Y.; Takayama, K.; Witt, M.; Vadala, G.; Oyster, N.; Otsuka, T.; et al. Use of an antifibrotic agent improves the effect of platelet-rich plasma on muscle healing after injury. J. Bone Joint Surg. Am. 2013, 95, 980-988. [CrossRef] [PubMed]

22. Nozaki, M.; Li, Y.; Zhu, J.; Ambrosio, F.; Uehara, K.; Fu, F.H.; Huard, J. Improved muscle healing after contusion injury by the inhibitory effect of suramin on myostatin, a negative regulator of muscle growth. Am. J. Sports Med. 2008, 36, 2354-2362. [CrossRef] [PubMed]

23. Helal, M.A.; Shaheen, N.E.; Abu Zahra, F.A. Immunomodulatory capacity of the local mesenchymal stem cells transplantation after severe skeletal muscle injury in female rats. Immunopharmacol. Immunotoxicol. 2016, 38, 414-422. [CrossRef] [PubMed]

24. Kobayashi, M.; Ota, S.; Terada, S.; Kawakami, Y.; Otsuka, T.; Fu, F.H.; Huard, J. The combined use of losartan and muscle-derived stem cells significantly improves the functional recovery of muscle in a young mouse model of contusion injuries. Am. J. Sports Med. 2016, 44, 3256-3261. [CrossRef] [PubMed]

25. Jarvinen, T.A.; Jarvinen, M.; Kalimo, H. Regeneration of injured skeletal muscle after the injury. Muscles Ligaments Tendons J. 2013, 3, 337-345. [PubMed]

26. Winkler, T.; von Roth, P.; Radojewski, P.; Urbanski, A.; Hahn, S.; Preininger, B.; Duda, G.N.; Perka, C. Immediate and delayed transplantation of mesenchymal stem cells improve muscle force after skeletal muscle injury in rats. J. Tissue Eng. Regen. Med. 2012, 6, s60-s67. [CrossRef] [PubMed]

27. Barash, I.A.; Mathew, L.; Ryan, A.F.; Chen, J.; Lieber, R.L. Rapid muscle-Specific gene expression changes after a single bout of eccentric contractions in the mouse. Am. J. Physiol. Cell Physiol. 2004, 286, C355-C364. [CrossRef] [PubMed]

28. Warren, G.L.; Summan, M.; Gao, X.; Chapman, R.; Hulderman, T.; Simeonova, P.P. Mechanisms of skeletal muscle injury and repair revealed by gene expression studies in mouse models. J. Physiol. 2007, 582, 825-841. [CrossRef] [PubMed] 
29. Lefaucheur, J.P.; Gjata, B.; Lafont, H.; Sebille, A. Angiogenic and inflammatory responses following skeletal muscle injury are altered by immune neutralization of endogenous basic fibroblast growth factor, insulin-like growth factor-1 and transforming growth factor- $\beta$ 1. J. Neuroimmunol. 1996, 70, 37-44. [CrossRef]

30. Heiderscheit, B.C.; Sherry, M.A.; Silder, A.; Chumanov, E.S.; Thelen, D.G. Hamstring strain injuries: Recommendations for diagnosis, rehabilitation, and injury prevention. J. Orthop. Sports Phys. Ther. 2010, 40, 67-81. [CrossRef] [PubMed]

31. Lowe, D.A.; Warren, G.L.; Ingalls, C.P.; Boorstein, D.B.; Armstrong, R.B. Muscle function and protein metabolism after initiation of eccentric contraction-induced injury. J. Appl. Physiol. 1995, 79, 1260-1270. [PubMed]

32. Warren, G.L.; Ingalls, C.P.; Shah, S.J.; Armstrong, R.B. Uncoupling of in vivo torque production from EMG in mouse muscles injured by eccentric contractions. J. Physiol. 1999, 515, 609-619. [CrossRef] [PubMed]

33. Pratt, S.J.P.; Lovering, R.M. A stepwise procedure to test contractility and susceptibility to injury for the rodent quadriceps muscle. J. Boil. Methods 2014, 1, e8. [CrossRef] [PubMed]

34. Lieber, R.L.; Schmitz, M.C.; Mishra, D.K.; Friden, J. Contractile and cellular remodeling in rabbit skeletal muscle after cyclic eccentric contractions. J. Appl. Physiol. 1994, 77, 1926-1934. [PubMed]

35. McCully, K.K.; Faulkner, J.A. Characteristics of lengthening contractions associated with injury to skeletal muscle fibers. J. Appl. Physiol. 1986, 61, 293-299. [PubMed]

36. Almekinders, L.C.; Gilbert, J.A. Healing of experimental muscle strains and the effects of nonsteroidal inflammatory medicine. Am. J. Sports Med. 1986, 14, 303-308. [CrossRef] [PubMed]

37. Jarvinen, T.A.; Jarvinen, T.L.; Kaariainen, M.; Aarimaa, V.; Vaittinen, S.; Kalimo, H.; Jarvinen, M. Muscle injuries: Optimising recovery. Best Pract. Res. Clin. Rheumatol. 2007, 21, 317-331. [CrossRef] [PubMed]

38. Wang, L.; Cao, L.; Shansky, J.; Wang, Z.; Mooney, D.; Vandenburgh, H. Minimally invasive approach to the repair of injured skeletal muscle with a shape-memory scaffold. Mol. Ther. 2014, 22, 1441-1449. [CrossRef] [PubMed]

39. Li, M.T.; Willett, N.J.; Uhrig, B.A.; Guldberg, R.E.; Warren, G.L. Functional analysis of limb recovery following autograft treatment of volumetric muscle loss in the quadriceps femoris. J. Biomech. 2014, 47, 2013-2021. [CrossRef] [PubMed]

40. Sam, M.; Shah, S.; Friden, J.; Milner, D.J.; Capetanaki, Y.; Lieber, R.L. Desmin knockout muscles generate lower stress and are less vulnerable to injury compared with wild-type muscles. Am. J. Physiol. Cell Physiol. 2000, 279, C1116-C1122. [PubMed]

41. Mair, S.D.; Seaber, A.V.; Glisson, R.R.; Garrett, W.E., Jr. The role of fatigue in susceptibility to acute muscle strain injury. Am. J. Sports Med. 1996, 24, 137-143. [CrossRef] [PubMed]

42. De Smet, A.A.; Best, T.M. MR imaging of the distribution and location of acute hamstring injuries in athletes. Am. J. Roentgenol. 2000, 174, 393-399. [CrossRef] [PubMed]

43. Friden, J.; Lieber, R.L. Segmental muscle fiber lesions after repetitive eccentric contractions. Cell Tissue Res. 1998, 293, 165-171. [CrossRef] [PubMed]

44. Lieber, R.L.; Friden, J. Selective damage of fast glycolytic muscle fibers with eccentric contraction of the rabbit tibialis anterior. Acta. Physiol. Scand. 1988, 133, 587-588. [CrossRef] [PubMed]

45. Appell, H.J.; Soares, J.M.; Duarte, J.A. Exercise, muscle damage and fatigue. Sports Med. 1992, 13, $108-115$. [CrossRef] [PubMed]

46. Brockett, C.L.; Morgan, D.L.; Gregory, J.E.; Proske, U. Damage to different motor units from active lengthening of the medial gastrocnemius muscle of the cat. J. Appl. Physiol. 2002, 92, 1104-1110. [CrossRef] [PubMed]

47. Denies, M.S.; Johnson, J.; Maliphol, A.B.; Bruno, M.; Kim, A.; Rizvi, A.; Rustici, K.; Medler, S. Diet-induced obesity alters skeletal muscle fiber types of male but not female mice. Physiol. Rep. 2014, 2, e00204. [CrossRef] [PubMed]

48. Best, T.M.; McCabe, R.P.; Corr, D.T.; Vanderby, R. Evaluation of a new method to create a standardized muscle stretch injury. Med. Sci. Sports Sci. 1998, 30, 200-205. [CrossRef]

(C) 2016 by the authors; licensee MDPI, Basel, Switzerland. This article is an open access article distributed under the terms and conditions of the Creative Commons Attribution (CC-BY) license (http://creativecommons.org/licenses/by/4.0/). 